\title{
Probing the inverse trans influence in americium and lanthanide tribromide tris(tricyclohexylphosphine oxide $) \dagger$
}

Cory J. Windorff, Cristian Celis-Barros, Joseph M. Sperling, Noah C. McKinnon, Thomas E. Albrecht-Schmitt*

Department of Chemistry and Biochemistry, Florida State University, 95 Chieftan Way, RM. 118 DLC, Tallahassee, Florida 32306, USA. E-mail: talbrechtschmitt@fsu.edu;

$\dagger$ Electronic supplementary information (ESI) available. Photographs of compounds, NMR spectra, electronic absorption spectra, additional theoretical calculation and crystallographic details for CCDC \#\#\#\#\#\#-\#\#\#\#\#.

ORCID: Cory J. Windorff: 0000-0002-5208-9129; Cristian Celis-Barros: 0000-0002-4685-5229; Joseph M. Sperling: 0000-0003-1916-5633; Thomas E. Albrecht-Schmitt: 0000-0002-2989-3311

\begin{abstract}
The synthesis, characterization, and theoretical analysis of meridional americium tribromide tris(tricyclohexylphosphine oxide), mer-AmBr $\mathbf{3}\left(\mathbf{O P c y}_{3}\right)_{3}$ has been achieved and is compared with its early lanthanide (La to $\mathrm{Nd}$ ) analogs. The data show that homo trans ligands show significantly shorter bonds than the cis or hetero trans ligands. This is particularly pronounced in the americium compound. DFT along with multiconfigurational CASSCF calculations show that the contraction of the bonds relates qualitatively with overall covalency, i.e. americium shows the most covalent interactions compared to lanthanides. . However, the involvement of the $5 p$ and $6 p$ shells in bonding follows a different order, namely cerium $>$ neodymium $\sim$ americium. This study provides further insight into the mechanisms by which ITI operates in low-valent $f$-block complexes.
\end{abstract}




\section{Introduction}

Phosphine oxides are highly stable ligands that have been utilized primarily for catalysis on elements across the periodic table. ${ }^{1}$ The study of phosphine oxides with $f$-elements has primarily focused on their use in extraction processes $^{2-5}$ and in (pseudo)halide/nitrate $f$ element starting materials. ${ }^{6-9}$ The effect of two ligands trans to one another is most prototypically examined in the actinyls, $\mathrm{AnO}_{2}{ }^{\mathrm{n}+}$, where the trans-oxygens display unusually short bond distances and high bond strength, best described as bond order of three. ${ }^{10}$ This effect, termed the inverse trans influence (ITI) has become the focus of several experimental and theoretical investigations. ${ }^{11-17}$ A prototypical examination on the effect of ITI is through the use or meridional octahedral compounds, e.g. mer- $\mathrm{MX}_{3} \mathrm{~L}_{3}$ Figure 1, which has been thoroughly studied in the transition metal series, but is significantly less studied in the $f$ block. ${ }^{18}$ However, the primary focus of structural and theoretical studies on actinide molecules displaying the ITI effect have been focused on high valent, +4 to +6 , oxidation states. $^{13,19}$ Lanthanides have only been subjected to structural studies in the +3 oxidation state $^{12,20}$ with some analysis of $\mathrm{Ce}(\mathrm{IV})$ and hypothetical $\operatorname{Pr}(\mathrm{IV})$ and $\mathrm{Tb}(\mathrm{IV})$ molecules. ${ }^{15,17}$ The amount of ITI can be quantified as a percentage that implies that the lower the percentage value the larger the ITI effect, Equation 1, where $r=$ bond distance, $M=$ metal, $X$ $=$ neutral or anionic ligand. ${ }^{21}$

$$
\mathrm{ITI}=\frac{\mathrm{r}\left(\mathrm{M}-\mathrm{X}_{\text {trans }}\right)}{\mathrm{r}\left(\mathrm{M}-\mathrm{X}_{\mathrm{cis}}\right)} \times 100
$$




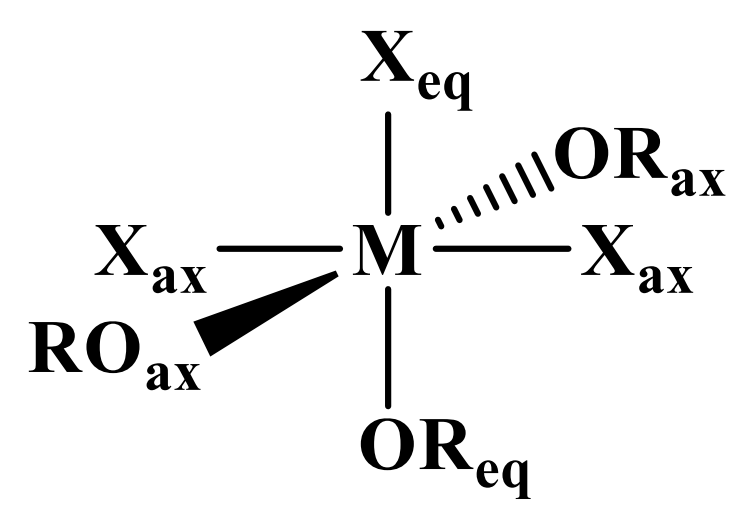

Figure 1. General depiction of ligand designations in $m e r-\mathrm{MX}_{3} \mathrm{~L}_{3}$.

The minor actinides, Am and $\mathrm{Cm}$, contribute high levels of radiation and heat in spent nuclear fuel. Long-lived isotopes of Am $\left[{ }^{241} \mathrm{Am}\left(\mathrm{t}_{1 / 2}=432 \mathrm{y}\right),{ }^{243} \mathrm{Am}\left(\mathrm{t}_{1 / 2}=7370 \mathrm{y}\right)\right]$ can be transmuted into radionuclides with a much shorter-half life, which is important for the end of the nuclear fuel cycle. However, the separation of these minor actinides from other fission products, such as lanthanides, remains a difficult problem. The additional separation of $\mathrm{Am}^{\mathrm{III}} / \mathrm{Cm}^{\mathrm{III}}$ is a great challenge due to their similar chemical properties and ionic radii. Phosphine oxide ligands have recently demonstrated relatively high selectivity for the Am$\mathrm{Cm}$ pair in the form of $\left(\mathrm{Ph}_{2} \mathrm{PyPO}\right)_{2} \mathrm{M}\left(\mathrm{NO}_{3}\right)_{3} \cdot{ }^{22}$ Although phosphine oxides are heavily utilized in separation of $f$-elements relevant to the nuclear fuel cycle, there have been few crystallographic studies for trans-uranium elements, and indeed only the mono and bis[Opy2,6- $\mathrm{CH}_{2}(\mathrm{Ph})_{2} \mathrm{PO}$, NOPOPO, adducts has been reported. ${ }^{23}$ Herein we examine the synthesis and structure in saturated tri-cyclohexylphosphine oxide adducts of $f$-element tribromides, and the effects of the ITI on tri-valent $f$-elements. 


\section{Experimental Details}

General Considerations. Caution! ${ }^{243} \mathrm{Am}\left(t_{1 / 2}=7,364\right.$ years $)$ and its daughters have high specific activity $\alpha$-particle and, $\gamma$ emitting radionuclides, and its use presents extreme hazards to human health. This research was conducted in radiological and nuclear facilities with appropriate analyses of these hazards and implementation of controls for the safe handling and manipulation of these toxic and radioactive materials.

Materials. All experiments were conducted in air with no attempt to exclude air or water. Reagents and solvents, $\mathrm{OPcy}_{3}\left(\mathrm{cy}=\right.$ cyclohexyl, $\mathrm{C}_{6} \mathrm{H}_{11}$, Alfa Aesar), $\mathrm{CDCl}_{3}$ (Cambridge), ${ }^{i} \mathrm{PrOH}$ (Sigma) $\mathrm{NH}_{3(\mathrm{aq})}$ (Baker) were purchased from commercial sources and used as received. $\mathrm{LnBr}_{3} \cdot 6 \mathrm{H}_{2} \mathrm{O}(\mathrm{Ln}=\mathrm{La}-\mathrm{Nd})$ were synthesized by dissolution of $\mathrm{Ln}_{2} \mathrm{O}_{3}$ in concentrated $\mathrm{HBr}$ and heated at $150{ }^{\circ} \mathrm{C}$ in a box furnace until viscous, then agitated, stirred until cooled to room temperature, dissolved in water and boiled down. This process was repeated twice. The product was washed with ether, to remove residual acid and $\mathrm{Br}_{2}$, until washings were colorless, dried under house vacuum for 10-15 min and stored in a desiccator and used with the assumed hydration number of six. All ${ }^{243} \mathrm{Am}$ synthetic manipulations were performed in a certified chemical fume hood, and a known concentration stock solution was prepared as previously described. ${ }^{24}$ Aqueous manipulations were performed with $>18 \Omega$ water from a Millipore purification system.

Instrumentation. All ${ }^{1} \mathrm{H},{ }^{13} \mathrm{C}\left\{{ }^{1} \mathrm{H}\right\}$ and ${ }^{31} \mathrm{P}\left\{{ }^{1} \mathrm{H}\right\}$ NMR spectra were recorded at 294(2) $\mathrm{K}$ on a Bruker $600 \mathrm{MHz}$ NMR spectrometer operating at 600.13, 150.90, and $242.94 \mathrm{MHz}$, respectively, for all lanthanide samples; the sample of ${ }^{243} \mathbf{A m B r}_{3}\left(\mathbf{O P c y}_{3}\right)_{3}$ was recorded at 295(2) K on a Bruker $400 \mathrm{MHz}$ NMR spectrometer operating at 400.17, 100.62, and 161.99 MHz, respectively. ${ }^{1} \mathrm{H}$ and ${ }^{13} \mathrm{C}\left\{{ }^{1} \mathrm{H}\right\}$ were referenced to internal solvent resonances, ${ }^{31} \mathrm{P}\left\{{ }^{1} \mathrm{H}\right\}$ spectra were referenced externally to $85 \% \quad \mathrm{H}_{3} \mathrm{PO}_{4}$. For radiologic containment, ${ }^{243} \mathrm{AmBr}_{3}\left(\mathrm{OPcy}_{3}\right)_{3}$ was dissolved in minimal $\mathrm{CDCl}_{3}$, transferred to a PTFE NMR tube liner, 
sealed, checked for contamination, placed inside a high quality borosilicate NMR tube, and checked again for contamination before being transported to the spectrometer. Due to the paramagnetism of $\mathrm{Am}^{3+}, \mathrm{Ce}^{3+}, \mathrm{Pr}^{3+}$ and $\mathrm{Nd}^{3+}$, and in particular the small sample size of ${ }^{243} \mathrm{AmBr}_{3}\left(\mathrm{OPcy}_{3}\right)_{3}$, only unambiguously identifiable peaks are assigned. Single crystal UV/vis/NIR measurements were made using a CRAIC microphotospectrometer on single crystals from 320 to $1700 \mathrm{~nm}$. Single crystals of the lanthanide complexes were mounted on nylon cryoloops with Paratone-N oil. Crystals of ${ }^{243} \mathbf{A m B r}_{3}\left(\mathbf{O P c y}_{3}\right)_{3}$ was mounted with appropriate layers of containment. Crystallographic data from all single crystals were collected on a Bruker D8 Quest diffractometer with a Photon 100 complementary metaloxide-semiconductor (CMOS) detector, and cooled to 120(2) or 130(2) K using an Oxford Cryostream or CRYO Industries low-temperature device. The instrument was equipped with graphite monochromatized Mo K $\alpha$ X-ray source $(\lambda=0.71073 \AA)$. The APEX3 ${ }^{25}$ program package was used to determine the unit-cell parameters and for data collection. The raw frame data was processed using $\mathrm{SAINT}^{26}$ and $\mathrm{SADABS}^{27}$ to yield the reflection data file. Subsequent calculations were carried out using the SHELXTL ${ }^{28,29}$ or OLEX2 $2^{30}$ programs.

Theoretical Methods. The coordinates of $\mathbf{M B r}_{3}\left(\mathbf{O P c y}_{3}\right)_{3}(\mathrm{M}=\mathrm{Am}, \mathrm{Ce}, \mathrm{Nd})$ for the calculations were obtained directly from the crystal structure to keep the constraints imposed by the solid-state packing. To utilize multiconfigurational calculations, the complete active space self-consistent field (CASSCF) approximation ${ }^{31}$ was used as implemented in the ORCA 4.1.1 program. ${ }^{32}$ Wave functions were obtained utilizing the SARC-TZVP basis set for the metal centers and the Def2-TZVP basis functions for the rest of the atoms. The active space considered were $n$ electrons $(n=1,3,6$ for $\mathrm{Ce}, \mathrm{Nd}$, and $\mathrm{Am})$ in the seven $f$ orbitals giving rise to a $\operatorname{CAS}(n, 7)$. Scalar relativistic effects were included by the second-order Douglas-Kroll-Hess (DKH2) Hamiltonian. State interactions via quasi-degenerate perturbation theory (QDPT) were used to correct the wave function for spin-orbit coupling 
(SOC). The resulting wave functions (SO-CAS) were used to analyze the nature of the ground and low-lying excited states, whereas the scalar relativistic wave functions (SR-CAS) were used for further bonding analysis.

The nature of the chemical bonds was addressed performing a topological analysis of the electron density using Bader's quantum theory of atoms in molecules (QTAIM) analysis. Key elements within QTAIM were extracted such as the electron density, delocalization indices, and energy densities at the interatomic region (bond critical point, $\mathrm{BCP}$ ) which have been employed previously for this aim. ${ }^{33-41}$ The covalency was analyzed, on one hand, by changes in the concentration of the electron density at the BCP along with changes in the delocalization indices. On the other hand, energy densities show the polarization of the covalent bond by looking at the ratios between potential $[\mathrm{V}(\mathrm{r})]$ and kinetic $[\mathrm{G}(\mathrm{r})]$ energy densities, which for partial covalent bonds lie in between values of 1 and 2. The total energy density shows the degree of covalency that is represented by the level of predominance of the potential over the kinetic energy density. ${ }^{42}$

A model system was also investigated where the cyclohexyl groups were replaced by methyl groups to simplify the molecular orbital energy diagram picture and allow the observations between the Am, $\mathrm{Ce}$ and $\mathrm{Nd}$ complexes to be made. The methyl groups were reoptimized while the rest of the molecule was kept frozen to conserve the crystal structure of the metal surrounding atoms. These calculations were performed in the ADF2019 suite ${ }^{43,44}$ using the PBE functional along with the TZP basis set. Frozen-core and all-electron calculations were performed for the full structure to prove the role of $5 / 6 p$ orbitals in the stabilization of the complexes at the same level of theory. Additionally, ligand-field $\mathrm{DFT}^{45,46}$ was used to examine the reduction of the inter-electronic repulsion within the $5 / 6 p$ shell due to central-field and symmetry-restricted covalency. The procedure used herein has been previously described for $\mathrm{Cs}_{2} \mathrm{KYF}_{6}: \mathrm{Pr}^{3+}{ }^{45}$ where occupation numbers in the $f$-shell were 
allowed to be fractional. The reductions were obtained not only with respect to the free-ions but also compared to the nona-aquo complexes, $\left[\mathrm{M}\left(\mathrm{H}_{2} \mathrm{O}\right)_{9}\right]^{3+}$, where the geometries were taken from the crystalized structures in the literature. ${ }^{47-49}$

Synthesis of ${ }^{243} \mathrm{AmBr}_{3}\left(\mathrm{OPcy}_{3}\right)_{3}$. An aliquot of ${ }^{243} \mathrm{Am}(3.0 \mathrm{mg}, 12 \mu \mathrm{mol})$ was drawn from a 2 $\mathrm{M} \mathrm{HCl}$ stock solution and precipitated with excess $\mathrm{NH}_{3(\mathrm{aq})}$ to give a pale yellow solid naïvely formulated as $\mathrm{Am}(\mathrm{OH})_{3}$, washed with water $(2 \times 2 \mathrm{~mL})$, suspended in $\sim 1 \mathrm{~mL}$ of water and dissolved with $\mathrm{HBr}$ (concentrated, $\sim 0.5 \mathrm{~mL}$ ) to give a yellow solution. The yellow solution was transferred to a $20 \mathrm{~mL}$ scintillation vial, placed under a heat lamp and gently evaporated to a yellow residue formulated as $\mathrm{AmBr}_{3} \bullet \mathrm{nH}_{2} \mathrm{O}$. The residue was dissolved in ${ }^{i} \mathrm{PrOH}(1.50$ $\mathrm{mL})$ to give a dark yellow solution. A colorless solution of $\mathrm{OPcy}_{3}(11 \mathrm{mg}, 38 \mu \mathrm{mol})$ in ${ }^{i} \mathrm{PrOH}$ (1.00 mL) was added to the Am solution, which quickly became turbid and clear again. The solution was capped and left to stand undisturbed. Over $3 \mathrm{~h}$ amber colored X-ray quality crystals were deposited. A small sample was withdrawn for spectroscopy (single crystal Xray diffraction and solid state UV/vis/NIR). The solution was capped and left to stand for 3 days to allow further crystallization. The mother liquor was decanted, washed with $\mathrm{Et}_{2} \mathrm{O}(3 \times$ $0.5 \mathrm{~mL}$ ), dried in air and transferred to a glovebox dedicated to actinide chemistry to give $\mathrm{AmBr}_{3}\left(\mathbf{O P c y}_{3}\right)_{3}$ as a yellow/brown crystalline solid, $9.0 \mathrm{mg}, 54 \% .{ }^{1} \mathrm{H} \mathrm{NMR}\left(\mathrm{CDCl}_{3} ; 400\right.$ MHz) $\delta: 1.80$ (br, s, cy), 1.67 (br, s, cy), 1.39 (br, s, cy), 1.14 (br, s, cy); ${ }^{13} \mathrm{C}\left\{{ }^{1} \mathrm{H}\right\}$ NMR $\left(\mathrm{CDCl}_{3} ; 101 \mathrm{MHz}\right) \delta: 27.08\left({ }^{2} J_{\mathrm{PC}}=27 \mathrm{~Hz}, c y\right), 26.15(c y) 25.90(c y) ;{ }^{31} \mathrm{P}\left\{{ }^{1} \mathrm{H}\right\} \mathrm{NMR}\left(\mathrm{CDCl}_{3}\right.$; $162 \mathrm{MHz}) \delta: 108.89\left(\mathrm{~s}, v_{1 / 2} 141.1 \mathrm{~Hz}\right)$. Due to the weak paramagnetism and small sample size ${ }^{1} \mathrm{H}$ integration is ambiguous and ${ }^{1} \mathrm{H}$ and ${ }^{13} \mathrm{C}\left\{{ }^{1} \mathrm{H}\right\}$ peak assignments are tentative, see ESI. UV/vis/NIR [ $\lambda_{\max }, \mathrm{nm}\left(\mathrm{cm}^{-1}\right)$, single crystal]: $340.0 \mathrm{~nm}(29,411)$ charge transfer, 368.4 $(27,148){ }^{5} \mathrm{G}_{2^{\prime}}, 380.9(26,252){ }^{5} \mathrm{G}_{4^{\prime}}, 433.4(23,074){ }^{5} \mathrm{H}_{4^{\prime}}, 457.5(21,856){ }^{5} \mathrm{G}_{2^{\prime}}, 477.0(20,695)$ ${ }^{5} \mathrm{D}_{2^{\prime}}, 508.0(19,685){ }^{5} \mathrm{~L}_{6^{\prime}}, 524.2(19,075){ }^{5} \mathrm{~L}_{6^{\prime}}, 777.4(12,863){ }^{7} \mathrm{~F}_{6^{\prime}}, 805.8(12,422){ }^{7} \mathrm{~F}_{6^{\prime}}, 823.2$ $(12,147){ }^{7} \mathrm{~F}_{6^{\prime}}, 1042.6(9591){ }^{7} \mathrm{~F}_{4^{\prime}}$. 
General Synthesis of $\operatorname{LnBr}_{3}\left(\mathrm{OPcy}_{3}\right)_{3}$, $(\mathbf{L n}=\mathrm{La}, \mathrm{Ce}, \mathrm{Pr}, \mathrm{Nd})$. As an alternative to the literature ${ }^{50}$ a colorless solution of $\mathrm{OPcy}_{3}(18 \mathrm{mg}, 61 \mu \mathrm{mol})$ in ${ }^{i} \mathrm{PrOH}(1.0 \mathrm{~mL})$ was added to a yellow solution of $\mathrm{LnBr}_{3} \bullet 6 \mathrm{H}_{2} \mathrm{O}(\sim 10 \mathrm{mg}, \sim 20 \mu \mathrm{mol})$ in ${ }^{i} \mathrm{PrOH}(1.5 \mathrm{~mL})$ causing the solution to become turbid and then clear. The vial was capped and left to stand overnight during which colorless X-ray quality crystals were deposited. A small sample was withdrawn for spectroscopy (single crystal X-ray diffraction and solid state UV/vis/NIR). The mother liquor was decanted, washed with $\mathrm{Et}_{2} \mathrm{O}(3 \times 0.5 \mathrm{~mL})$, dried in air and briefly dried under reduced pressure to give $\mathbf{L n B r}_{3}\left(\mathbf{O P c y}_{3}\right)_{3}$ as a crystalline solid. All products were confirmed by single crystal X-ray crystallography.

$\mathbf{L a B r}_{\mathbf{3}}\left(\mathbf{O P c y}_{\mathbf{3}}\right)_{3}$. Colorless $\mathbf{L a B r}_{\mathbf{3}}\left(\mathbf{O P c y}_{\mathbf{3}}\right)_{\mathbf{3}} 20 \mathrm{mg}, 80 \%$. ${ }^{1} \mathrm{H} \mathrm{NMR}\left(\mathrm{CDCl}_{3} ; 600 \mathrm{MHz}\right) \delta: 4.305$ (s, 2H, $\left.\mathrm{H}_{2} \mathrm{O}\right), 2.068(\mathrm{~m}, 8 \mathrm{H}, c y), 1.991(\mathrm{~m}, 18 \mathrm{H}, c y), 1.842(\mathrm{~m}, 18 \mathrm{H}, c y), 1.700(\mathrm{~m}, 9 \mathrm{H}, c y)$, $1.600(\mathrm{~m}, 18 \mathrm{H}, c y), 1.352-1.261(\mathrm{~m}, 28 \mathrm{H}, c y) ;{ }^{13} \mathrm{C}\left\{{ }^{1} \mathrm{H}\right\} \mathrm{NMR}\left(\mathrm{CDCl}_{3} ; 151 \mathrm{MHz}\right) \delta: 34.772$ $\left({ }^{1} J_{\mathrm{CP}}=34.8 \mathrm{~Hz}, i-c y\right), 26.893\left({ }^{2} J_{\mathrm{CP}}=26.94 \mathrm{~Hz}, c y\right), 25.996(c y), 25.901(c y) ;{ }^{31} \mathrm{P}\left\{{ }^{1} \mathrm{H}\right\} \mathrm{NMR}$ $\left(\mathrm{CDCl}_{3} ; 243 \mathrm{MHz}\right) \delta: 60.314\left(\mathrm{~s}, v_{1 / 2} 151.9 \mathrm{~Hz}\right)$.

$\mathrm{CeBr}_{3}\left(\mathbf{O P c y}_{3}\right)_{3}$. Orange $\mathrm{CeBr}_{3}\left(\mathrm{OPcy}_{3}\right)_{3} 20 \mathrm{mg}, 75 \% .{ }^{1} \mathrm{H} \mathrm{NMR}\left(\mathrm{CDCl}_{3} ; 600 \mathrm{MHz}\right) \delta: 5.29$ (br, s, 9H, cy), 3.64 (br, s, 18H, cy), 2.68 (br, s, 18H, cy), 2.01 (s, 18H, cy), 1.82 (s, 25H, cy), $1.22(\mathrm{br}, \mathrm{s}, 10 \mathrm{H}, c y) ;{ }^{13} \mathrm{C}\left\{{ }^{1} \mathrm{H}\right\} \mathrm{NMR}\left(\mathrm{CDCl}_{3} ; 151 \mathrm{MHz}\right) \delta: 38.76\left({ }^{1} J_{\mathrm{CP}}=38.8 \mathrm{~Hz}, i-c y\right), 27.51$ (cy), $26.06(c y) ;{ }^{31} \mathrm{P}\left\{{ }^{1} \mathrm{H}\right\} \mathrm{NMR}\left(\mathrm{CDCl}_{3} ; 243 \mathrm{MHz}\right) \delta: 109.48\left(\mathrm{~s}, v_{1 / 2} 240.4 \mathrm{~Hz}\right) . \mathrm{UV} / \mathrm{vis} / \mathrm{NIR}$ $\left[\lambda_{\max }, \mathrm{nm}\left(\mathrm{cm}^{-1}\right)\right.$, single crystal]: $339.8(29,479)$ charge transfer.

$\operatorname{PrBr}_{3}\left(\mathbf{O P c y}_{3}\right)_{3}$. Colorless $\operatorname{PrBr}_{3}\left(\mathbf{O P c y}_{3}\right)_{3} 22 \mathrm{mg}, 83 \% .{ }^{1} \mathrm{H}$ NMR $\left(\mathrm{CDCl}_{3} ; 600 \mathrm{MHz}\right) \delta: 20.85$ (br, s, $\left.v_{1 / 2}=1468 \mathrm{~Hz}, 5 \mathrm{H}, c y\right), 13.55\left(\mathrm{br}, \mathrm{s}, v_{1 / 2}=862 \mathrm{~Hz}, 16 \mathrm{H}, c y\right), 10.52\left(\mathrm{br}, \mathrm{s}, v_{1 / 2}=926\right.$ Hz, 14H, cy), 4.8 (br, s, 20H, cy), 3.40 (br, s, 21H, cy), 2.72 (br, s, 12H, cy), 1.44 (br, s, 11H, cy); ${ }^{13} \mathrm{C}\left\{{ }^{1} \mathrm{H}\right\}$ NMR $\left(\mathrm{CDCl}_{3} ; 151 \mathrm{MHz}\right) \delta: 36.94(c y), 30.54(c y), 27.70(c y) ;{ }^{31} \mathrm{P}\left\{{ }^{1} \mathrm{H}\right\} \mathrm{NMR}$ $\left(\mathrm{CDCl}_{3} ; 243 \mathrm{MHz}\right) \delta: 212.4\left(\mathrm{~s}, \mathrm{br}, v_{1 / 2} 4290\right)$. 
$\mathbf{N d B r}_{3}\left(\mathbf{O P c y}_{3}\right)_{3}$. Pale green $\mathbf{N d B r}_{3}\left(\mathbf{O P c y}_{3}\right)_{3} 19 \mathrm{mg}, 82 \% .{ }^{1} \mathrm{H} \mathrm{NMR}\left(\mathrm{CDCl}_{3} ; 600 \mathrm{MHz}\right) \delta$ : $11.77\left(\mathrm{br}, \mathrm{s}, v_{1 / 2}=590 \mathrm{~Hz}, 8 \mathrm{H}, c y\right), 7.39\left(\mathrm{br}, \mathrm{s}, v_{1 / 2}=320 \mathrm{~Hz}, 17 \mathrm{H}, c y\right.$, overlapping with $\mathrm{CDCl}_{3}$ ), 5.53 (br, s, $\left.v_{1 / 2}=400 \mathrm{~Hz}, 17 \mathrm{H}, c y\right), 3.05$ (br, s, 18H, cy), 2.53 (br, s, 19H, cy), 2.14 (br, s, $\left.v_{1 / 2}=11 \mathrm{H}, c y\right), 1.21(\mathrm{br}, \mathrm{s}, 11 \mathrm{H}, c y) ;{ }^{13} \mathrm{C}\left\{{ }^{1} \mathrm{H}\right\} \mathrm{NMR}\left(\mathrm{CDCl}_{3} ; 151 \mathrm{MHz}\right) \delta: 30.95(c y)$, $28.54(c y), 26.66(c y) ;{ }^{31} \mathrm{P}\left\{{ }^{1} \mathrm{H}\right\} \mathrm{NMR}\left(\mathrm{CDCl}_{3} ; 243 \mathrm{MHz}\right) \delta: 190.2\left(\mathrm{~s}\right.$, br, $\left.v_{1 / 2} 1366 \mathrm{~Hz}\right)$. UV/vis/NIR [ $\lambda_{\max }, \mathrm{nm}\left(\mathrm{cm}^{-1}\right)$, single crystal]: $532.0(18,798), 572.8(17,459), 576.6(17,342)$, 584.3 (17,114), 588.1 (17,003), 591.9 (16,893), $595.0(16,806), 599.6(16,678), 607.3$ $(16,467)$ all excitations belong to ${ }^{4} \mathrm{G}_{7 / 2},{ }^{4} \mathrm{G}_{5 / 2}$.

\section{Results and Discussion}

Synthesis. Previously published literature on $\mathrm{LnCl}_{3}\left(\mathrm{OPR}_{3}\right)_{\mathrm{x}}$ show that the products have poor solubility or are prone to speciation. ${ }^{51-53}$ The more solubilizing bromide anion was studied instead. The known $\mathbf{m e r}-\mathbf{L n B r}_{\mathbf{3}}\left(\mathbf{O P c y}_{\mathbf{3}}\right)_{\mathbf{3}}\left(\right.$ mer $=$ meridional; cy = cyclohexyl, $\left.\mathrm{C}_{6} \mathrm{H}_{11}\right)$ have been recently reported and give opportunity for extension to the trivalent actinides, though small lanthanides can speciate. ${ }^{50,54-56}$ There has been just one report of a single crystal AmBr compound, $\mathbf{A m B r}_{3}(\mathbf{T H F})_{4} \cdot{ }^{57}$

The previously reported syntheses of $\boldsymbol{m e r}-\mathbf{L n B r}_{3}(\mathbf{O P c y})_{3}$, $\left(\right.$ cy $=$ cyclohexyl, $\left.\mathrm{C}_{6} \mathrm{H}_{11}\right)$ utilized boiling ethanol and describe the complexes as having low solubility. ${ }^{50}$ By changing the alcohol to iso-propyl alcohol $\left({ }^{i} \mathrm{PrOH}\right)$ and working on a scale relevant to actinides, ie $\leq$ $0.02 \mathrm{mmol}$ of metal content, a smooth synthesis is obtained. This was extended to americium by starting from a stock solution of $\mathrm{AmCl}_{3} \bullet \mathrm{nH}_{2} \mathrm{O}$ in $\mathrm{HCl}$, precipitating the hydroxide and dissolving the product in $\mathrm{HBr}_{(\mathrm{aq})}$ and evaporated to dryness forming a putative $\mathrm{AmBr}_{3} \bullet \mathrm{nH}_{2} \mathrm{O}$. Combining the components in ${ }^{i} \mathrm{PrOH}$ initially forms a turbid solution which clarified within minutes and upon standing at room temperature, amber colored X-ray quality crystals formed 
within 2 h, Equation 2. A small sample was removed for spectroscopy and the solution was left to stand several days to increase the crystalline yield before work up, Figure 2.

1) $\mathrm{xs} \mathrm{NH}_{3(\mathrm{aq})}$

2) $x \mathrm{HBr}$

$\mathrm{AmCl}_{3}\left(\mathrm{H}_{2} \mathbf{O}\right)_{x}$

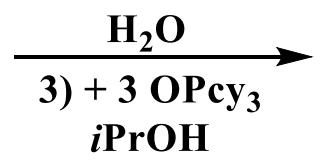

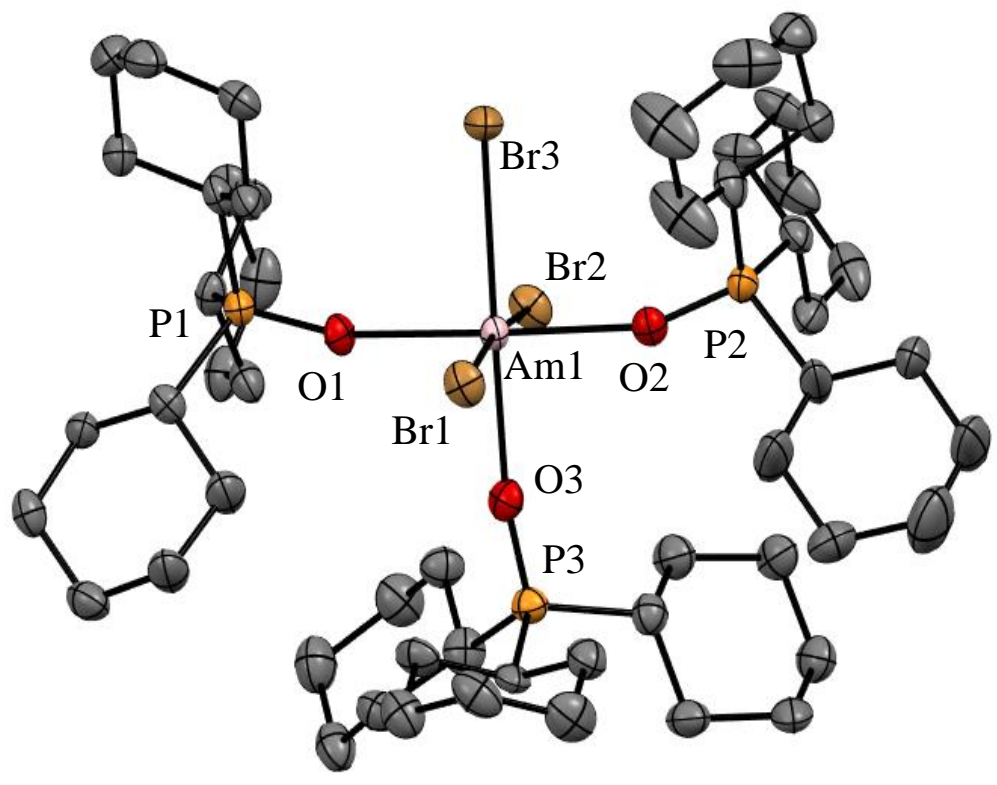

Figure 2. Thermal ellipsoid plot of $\mathbf{A m B r}_{3}\left(\mathbf{O P c y}_{3}\right)_{3}$ drawn at the 50\% probability level with hydrogen atoms omitted for clarity.

Crystallography. $\mathbf{A m B r}_{\mathbf{3}}\left(\mathbf{O P c y}_{\mathbf{3}}\right)_{3}$ crystallizes as the meridional isomer, mer$\mathrm{AmBr}_{3}\left(\mathrm{OPcy}_{3}\right)_{3}$, in the orthorhombic $\mathrm{Pca}_{1}$ space group and is isomorphous with its lanthanide analogs. ${ }^{25}$ Based on the Flack parameter, a small $(\leq 3 \%)$ enantiomorphic twin was dealt with using a TWIN/BASF refinement, see ESI. ${ }^{58}$ The Am-Br bond lengths fall into two 
classes, that of axial (ax) and equatorial (eq) ligands, where axial ligands consistent of a homo-ligand trans to the ligand of interest, and equatorial ligands where a hetero ligand is trans to the ligand of interest, Figure 1. The Am- $\mathrm{O}_{\mathrm{ax}}$ bond lengths are 2.302(7), and 2.312(7) $\AA$ while the $\mathrm{Am}-\mathrm{O}_{\mathrm{eq}}$ bond is $2.349(6) \AA$, a separation of $3 \sigma$. The $\mathrm{Am}-\mathrm{Br}_{\mathrm{ax}}$ atoms display a bond distance of 2.870(1), and 2.882(1) $\AA$ and the $\mathrm{Br}_{\mathrm{eq}}$ atom displays a significantly longer distance of 2.912(1) $\AA$. These values are all significantly longer than the $2.8222(6)$, 2.8445(6), and 2.8610(6) $\AA$ bond lengths reported in $\mathbf{A m B r}_{\mathbf{3}}(\mathbf{T H F})_{4}{ }^{57}$ However, all of the 2.466(4)-2.533(4) $\AA \mathrm{Am}-\mathrm{O}_{\mathrm{THF}}$ bond lengths in $\mathbf{A m B r}_{3}(\mathbf{T H F})_{4}$ are significantly longer than Am-O bond lengths in $\mathbf{A m B r}_{3}\left(\mathbf{O P c y}_{3}\right)_{3}$. The 2.34(1)-2.51(1) $\AA$ Am-O bond lengths reported for the NOPOPO ligand in $\mathbf{A m}(\mathbf{N O P O P O})\left(\mathbf{N O}_{3}\right)_{3}$ and $\left[\mathrm{Am}(\mathrm{NOPOPO})_{2}\left(\mathbf{N O}_{3}\right)\right]\left[\mathbf{N O}_{3}\right]_{2}$ $\left[\mathrm{NOPOP}=\operatorname{Bis}[(\right.$ phosphino $)$ methyl $]$ pyridine-1-oxide, Opy-2,6- $\left.\mathrm{CH}_{2}(\mathrm{Ph})_{2} \mathrm{PO}\right]$ are only comparable to 2.349(6) $\AA \mathrm{Am}-\mathrm{O}_{\text {eq }}$ bond since the $\mathrm{Am}-\mathrm{O}_{\mathrm{ax}}$ bond lengths are all significantly shorter, Table 1. ${ }^{23}$ All of the $\mathrm{X}-\mathrm{Am}-\mathrm{Y}$ bond angles are between $85.2(2)-95.60(5)^{\circ}$ for cis ligands and 172.74(3)-178.1(2) ${ }^{\circ}$ for trans ligands, see ESI.

Table 1. Comparisons of Am-O bond lengths $(\AA)$ in selected Am complexes.

\begin{tabular}{|c|c|c|c|c|}
\hline & $\mathrm{Am}^{-\mathrm{OPcy}_{3 \mathrm{ax}}}$ & Am-OPcy3eq & $\mathrm{Am}-\mathrm{O}_{\mathrm{NL}}$ & $\mathrm{Am}-\mathrm{O}_{\mathrm{PL}}$ \\
\hline $\operatorname{AmBr}_{3}\left(\mathrm{OPcy}_{3}\right)_{3}$ & $2.302(7), 2.312(7)$ & $2.349(6)$ & & \\
\hline $\operatorname{Am}(\mathbf{L})\left(\mathbf{N O}_{3}\right)_{3}{ }^{23}$ & & & $2.417(9)$ & $2.38(1), 2.39(1)$ \\
\hline$\left[\mathrm{Am}(\mathrm{L})_{2}\left(\mathrm{NO}_{\mathbf{3}}\right)\right]\left[\mathrm{NO}_{3}\right]_{2}{ }^{23}$ & & & $\begin{array}{l}2.51(1) \\
2.506(9)\end{array}$ & $\begin{array}{l}2.39(1), 2.34(1), \\
2.38(1), 2.34(1)\end{array}$ \\
\hline
\end{tabular}

$\mathrm{L}=\mathrm{NOPOPO}, \mathrm{Opy}-2,6-\mathrm{CH}_{2}(\mathrm{Ph})_{2} \mathrm{PO}$

In the course of preparing the synthesis of $\mathbf{m e r}-\mathbf{A m B r}_{\mathbf{3}}\left(\mathbf{O P c y}_{3}\right)_{3}$, the analogous lanthanides, La-Nd, were examined using the modified synthesis stated above, since the 6coordinate radius of $\mathrm{Am}^{3+}, 0.975 \AA$, is most closely related to $\mathrm{Nd}^{3+}, 0.983 \AA{ }^{59}$ It was found 
that the $\mathrm{Nd}$ and $\mathrm{Pr}$ analogs, $\boldsymbol{m e r}-\mathrm{LnBr}_{3}\left(\mathrm{OPcy}_{3}\right)_{3}$, are isomorphous with the previously reported structures, except the half occupied lattice water was not located in our structures, see ESI. ${ }^{50}$ The Ce analog, $\boldsymbol{m e r}-\mathbf{C e B r}_{3}\left(\mathbf{O P c y}_{\mathbf{3}}\right)_{3}$ is not yet reported and the structure was collected. The La analog was reported in the $P 2_{1}$ space group with a lattice ethanol molecule, mer- $\mathrm{LaBr}_{\mathbf{3}}\left(\mathrm{OPcy}_{\mathbf{3}}\right)_{3} \mathbf{B}^{\bullet \mathbf{E t O H}}$, however upon synthesis in ${ }^{i} \mathrm{PrOH}$, the isomorphous $P c a 2_{1}$ unit cell was obtained and is reported here, see ESI. Crystals of $\mathbf{C e B r}_{3}\left(\mathbf{O P c y}_{3}\right)_{3}$ are orange, while crystals of the La, Pr and Nd analogs are all colorless. Bulk samples of $\mathbf{P r B r}_{\mathbf{3}}\left(\mathbf{O P c y}_{3}\right)_{\mathbf{3}}$ and $\mathbf{N d B r}_{3}\left(\mathbf{O P c y}_{3}\right)_{3}$ are pale yellow and pale green, respectively. The bond metrics of the lanthanides examined here all display the same axial/equatorial bonding patterns, that being axial ligands display much shorter bond lengths than equatorial ligands, with distorted octahedral geometries, see ESI.

With this data in hand, the calculations of ITI effect from Eq. 1 were carried out on the $\mathbf{M B r}_{\mathbf{3}}\left(\mathbf{O P c y}_{\mathbf{3}}\right)_{\mathbf{3}}(\mathrm{M}=\mathrm{Am}, \mathrm{La}, \mathrm{Ce}, \mathrm{Pr}, \mathrm{Nd})$ complexes examined here. The data show that a subtle increase in ITI effect is seen with decreasing ionic radius, Table 2, all of the data are within the error of one another. When the ITI calculations were repeated using the crystallographic data for the previously published $\mathbf{L n B r}_{\mathbf{3}}\left(\mathbf{O P c y}_{\mathbf{3}}\right)_{\mathbf{3}}$ compounds $(\mathrm{Ln}=\mathrm{La}, \mathrm{Pr}$, $\mathrm{Nd}, \mathrm{Gd}, \mathrm{Ho}$ ), as well as $\mathbf{L n I}_{\mathbf{3}}\left(\mathbf{E t}_{\mathbf{2}} \mathbf{O}\right)_{\mathbf{3}},{ }^{20} \mathbf{L n C l}_{\mathbf{3}}(\mathbf{H M P A})_{\mathbf{3}},{ }^{60-62}$ and the series $\mathbf{Y b X}_{\mathbf{3}}(\mathbf{T H F})_{\mathbf{3}}$ (X $=\mathrm{Cl}, \mathrm{Br}, \mathrm{I}) .{ }^{11,63,64}$ The data shows no clear trends or patterns with respect to lanthanide or halide identity, where the halide ligands usually show no ITI. The oxygen donors follow the pattern in terms of ITI values where: $\mathrm{Et}_{2} \mathrm{O}>\mathrm{THF}>\mathrm{HMPA}$, which appears counter intuitive since HMPA is regarded as a strong donor, while $\mathrm{Et}_{2} \mathrm{O}$ is regarded as a weak donor, see ESI for data tables. Without more sophisticated investigations and based on these small data sets, it is not clear what ligands affect the values for ITI calculations in terms of donor strength, steric bulk and crystallization effects. No analogous actinide compounds were located, likely 
due to the prevalence of the +4 oxidation state in the early actinides and the scarcity of transplutonium crystallographic data.

Table 2. Inverse trans influence calculated from Eq. 1 for the $\mathbf{M B r}_{3}\left(\mathbf{O P c y}_{3}\right)_{3}(\mathbf{M}=\mathrm{Am}, \mathrm{Nd}$, Pr, Ce, La) series. ${ }^{6}$

\begin{tabular}{cccccc}
\hline $\mathbf{M B r}_{\mathbf{3}}\left(\mathbf{O P c y}_{\mathbf{3}}\right)_{\mathbf{3}}$ & $\mathbf{A m}$ & $\mathbf{N d}$ & $\mathbf{P r}$ & $\mathbf{C e}$ & $\mathbf{L a}$ \\
\hline Radius $(\AA)^{\mathrm{a}}$ & 0.975 & 0.983 & 0.99 & 1.01 & 1.032 \\
\hline $\mathrm{ITI}_{\mathrm{M}-\mathrm{Br}}$ & $98.8(2)$ & $98.9(2)$ & $98.8(2)$ & $99.0(2)$ & $99.1(1)$ \\
$\mathrm{ITI}_{\mathrm{M}-\mathrm{O}}$ & $98.2(2)$ & $98.6(3)$ & $98.4(2)$ & $98.6(1)$ & $99.0(3)$ \\
${ }^{\mathrm{a}}$ 6-Coordinate Shannon Ionic Radius & & & & &
\end{tabular}

Electronic Absorption Spectroscopy. The electronic absorption spectroscopy for $\mathbf{A m B r}_{3}\left(\mathbf{O P c y}_{3}\right)_{3}$ shows an intense charge transfer band centered at $\lambda_{\max } 340 \mathrm{~nm}(29,411$ $\mathrm{cm}^{-1}$ ) in addition to the Laporte forbidden $5 f \rightarrow 5 f$ transitions characteristic of Am ${ }^{\text {III }}$. 55,66 With few exceptions, the energies of the absorptions are similar to those reported in the low temperature spectrum of $\mathrm{AmBr}_{3}$ and the recently reported spectrum of $\left(\mathrm{PPh}_{4}\right)_{3} \mathrm{AmCl}_{6}{ }^{67} \mathrm{The}$ characteristic ${ }^{5} \mathrm{~L}_{6^{\prime}}$ excitation reported at $510 \mathrm{~nm}\left(19,588 \mathrm{~cm}^{-1}\right)$ shifted to $508 \mathrm{~nm}\left(19,685 \mathrm{~cm}^{-}\right.$ ${ }^{1}$ ), Figure 3. The compound was not fluorescent at room temperature even with long integration times $(\leq 2000 \mathrm{~ms})$ at an excitation wavelength of 365 or $420 \mathrm{~nm}$. $\mathbf{C e B r}_{\mathbf{3}}\left(\mathbf{O P c y}_{\mathbf{3}}\right)_{\mathbf{3}}$ displays an intense charge transfer band with $\lambda_{\max }$ of $339 \mathrm{~nm}\left(29,479 \mathrm{~cm}^{-1}\right) . \mathbf{N d B r}_{\mathbf{3}}\left(\mathbf{O P c y}_{\mathbf{3}}\right)_{\mathbf{3}}$ reveals, sharp hypersensitive transitions of low intensity between 500-607 nm consistent with the ${ }^{4} \mathrm{G}_{7 / 2}$ and ${ }^{4} \mathrm{G}_{5 / 2}$ excitations, similar to the values reported for $\mathrm{NdBr}_{3(\mathrm{~g})}$ at $1195{ }^{\circ} \mathrm{C}$, while several of the typical $4 f \rightarrow 4 f$ transitions reported for $\mathrm{Nd}\left(\mathrm{ClO}_{4}\right)_{3(\mathrm{aq})}$ were not observed. ${ }^{68-70}$ $\mathbf{L a B r}_{\mathbf{3}}\left(\mathbf{O P c y}_{\mathbf{3}}\right)_{\mathbf{3}}$ and $\operatorname{PrBr}_{\mathbf{3}}\left(\mathbf{O P c y}_{\mathbf{3}}\right)_{\mathbf{3}}$ gave no UV/vis/NIR peaks between $320-1700 \mathrm{~nm}$. The former is typical of the $5 d^{0} 4 f^{0} \mathrm{La}^{3+}$ ion, while the latter is unusual for the $4 f^{2} \mathrm{Pr}^{3+}$ ion, ${ }^{70}$ this 
may be due to the pseudo inversion center present in $\mathbf{M B r}_{3}\left(\mathbf{O P c y}_{3}\right)_{3}$. Though the $\operatorname{Pr}^{3+}$ ion possesses hypersensitive ${ }^{3} \mathrm{P}_{2}$ and ${ }^{1} \mathrm{D}_{2}$ transitions at $444.4 \mathrm{~nm}\left(22,500 \mathrm{~cm}^{-1}\right)$ and $588.2 \mathrm{~nm}$ $\left(17,000 \mathrm{~cm}^{-1}\right)$, respectively, but were not observed through repeated collections, see ESI for spectra. ${ }^{69,70}$ None of the lanthanide compounds were fluorescent.

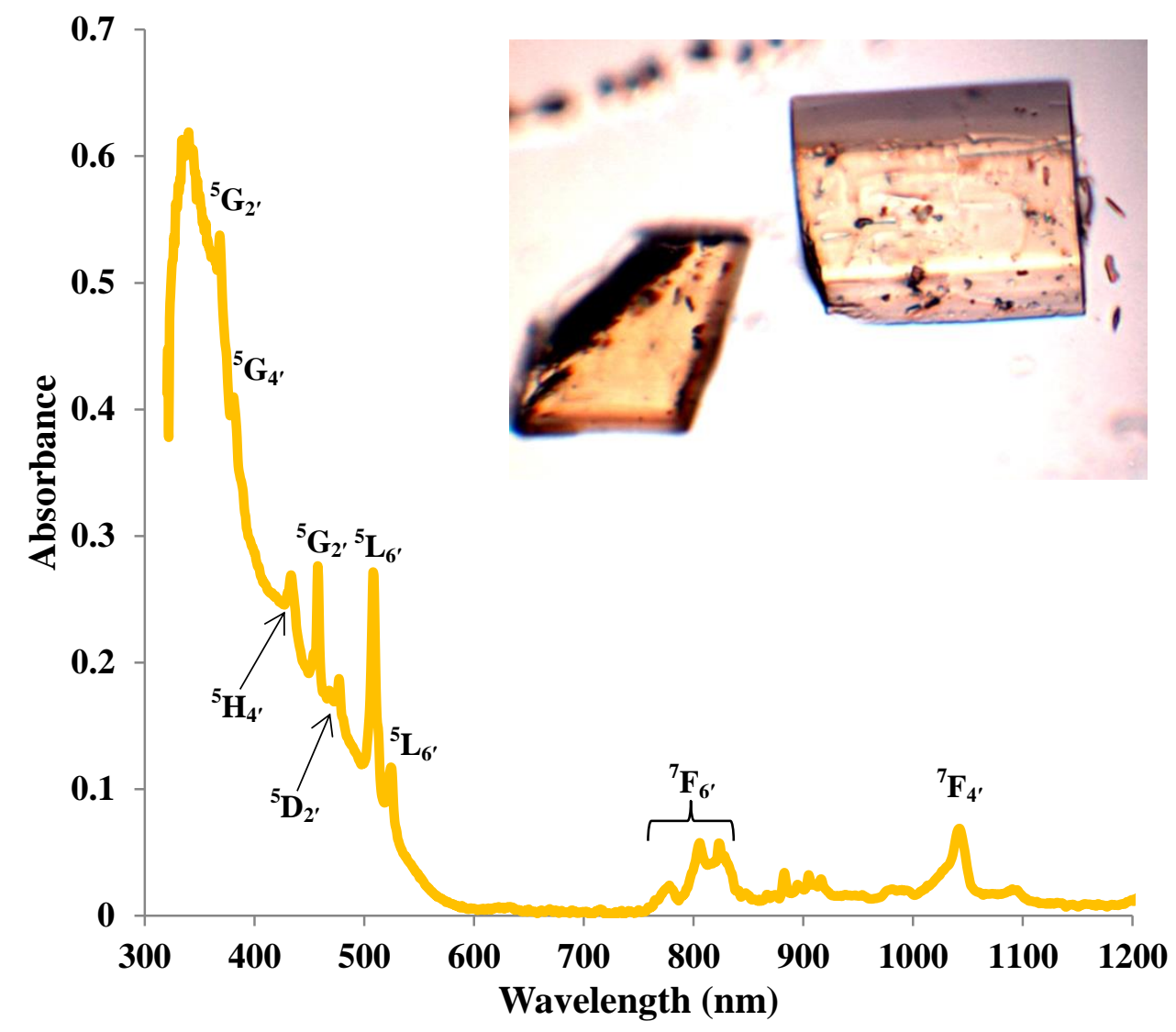

Figure 3. Solid state UV/vis/NIR of $\mathbf{A m B r}_{3}\left(\mathbf{O P c y}_{3}\right)_{3}$ at room temperature, with excitation assignments and photograph of crystals.

Multi-nuclear NMR Spectroscopy. In order to gain more insight into the system, and due to the convenient spectroscopic handle provided by the ${ }^{31} \mathrm{P}$ nucleus, ${ }^{1} \mathrm{H},{ }^{13} \mathrm{C}\left\{{ }^{1} \mathrm{H}\right\}$ and ${ }^{31} \mathrm{P}\left\{{ }^{1} \mathrm{H}\right\}$ multi nuclear NMR spectra were recorded. Due to radiological constraints and small sample sizes obtaining NMR spectra on americium samples can be difficult. Exceptions have included Evans' Method studies, ${ }^{71}$ a notable solid state MAS study of $\mathrm{AmO}_{2}{ }^{72}$ and the recent 
report of $\mathrm{Am}\left(\mathrm{C}_{5} \mathrm{Me}_{4} \mathrm{H}\right){ }_{3} .{ }^{73}$ Some ${ }^{31} \mathrm{P}\left\{{ }^{1} \mathrm{H}\right\}$ data has been reported previously for other $\mathbf{L n B r}_{3}\left(\mathbf{O P c y}_{3}\right)_{3}$ complexes, ${ }^{50}$ here we seek to add to this data and compare it with its americium analog. Because of the weak paramagnetism of the $5 f^{6} \mathrm{Am}^{3+}$ ion, $1.64 \mu_{\mathrm{B}}{ }^{71}$ a shorter relaxation time $(\mathrm{d} 1=1 \mathrm{sec})$ was utilized along with several extra scans to obtain a good signal for $\mathbf{A m B r}_{3}\left(\mathbf{O P c y}_{3}\right)_{3}$ at a shift of $\delta 108.89 \mathrm{ppm}$, Figure 4. To the best of our knowledge this is the first report of $\mathrm{a}^{31} \mathrm{P}$ NMR signal in an americium complex. The signal is similar in chemical shift to the $4 f^{1} \mathbf{C e B r}_{3}\left(\mathbf{O P c y}_{3}\right)_{3}$ at $\delta 109.48 \mathrm{ppm}$. Both signals are shifted down field from the diamagnetic $\mathbf{L a B r}_{3}\left(\mathbf{O P c y}_{3}\right)_{3}(\delta 60.314 \mathrm{ppm})$ and the free ligand $\mathrm{OPcy}$ $(\delta 50.574 \mathrm{ppm})$ which was recorded for comparison. The more paramagnetic $4 f^{2}$ and $4 f^{3}$ $\operatorname{PrBr}_{3}\left(\mathbf{O P c y}_{3}\right)_{3}$ and $\mathbf{N d B r}_{3}\left(\mathbf{O P c y}_{3}\right)_{3}$ are significantly shifted further down field $(\delta 212.4$ and $190.2 \mathrm{ppm}$, respectively) and are significantly broadened (4290 and $1366 \mathrm{~Hz}$, respectively), Figure 4. Due to the high fluxionality of the cyclohexyl rings the ${ }^{1} \mathrm{H}$ NMR spectra are complicated and provide limited information. In particular the paramagnetism in $\operatorname{PrBr}_{3}\left(\mathrm{OPcy}_{3}\right)_{3}$ and $\mathrm{NdBr}_{3}\left(\mathrm{OPcy}_{3}\right)_{3}$ give rise to several broad peaks over a range of about 20 ppm, some with widths over $1400 \mathrm{~Hz}$, see ESI for spectra. The ${ }^{13} \mathrm{C}\left\{{ }^{1} \mathrm{H}\right\}$ NMR spectra of $\mathbf{M B r}_{3}\left(\mathbf{O P c y}_{3}\right)_{3}$ show several signals and are consistent with a single chemical environment for the carbons. Due to the small sample size of $\mathbf{A m B r}_{\mathbf{3}}\left(\mathbf{O P c y}_{3}\right)_{3}$ only three of the expected four signals were observed, with the ipso-carbon likely being too broad and weak to be observed in this experiment, though a doublet at $\delta 27.08 \mathrm{ppm}$ with $J_{\mathrm{CP}}$ coupling constant of $27 \mathrm{~Hz}$ is consistent with the carbon $\alpha$ to the ipso-carbon. For the diamagnetic free ligand and $\mathbf{L a B r}_{3}\left(\mathbf{O P c y}_{3}\right)_{3}$ both 1-bond and 2-bond C-P coupling was observed with constants of ca 35 and $27 \mathrm{~Hz}$, respectively. While only the 1-bond C-P coupling was observed in $\mathrm{CeBr}_{3}\left(\mathrm{OPcy}_{3}\right)_{3}$ and no coupling was observed in the Pr and Nd compounds, see ESI for spectra. 


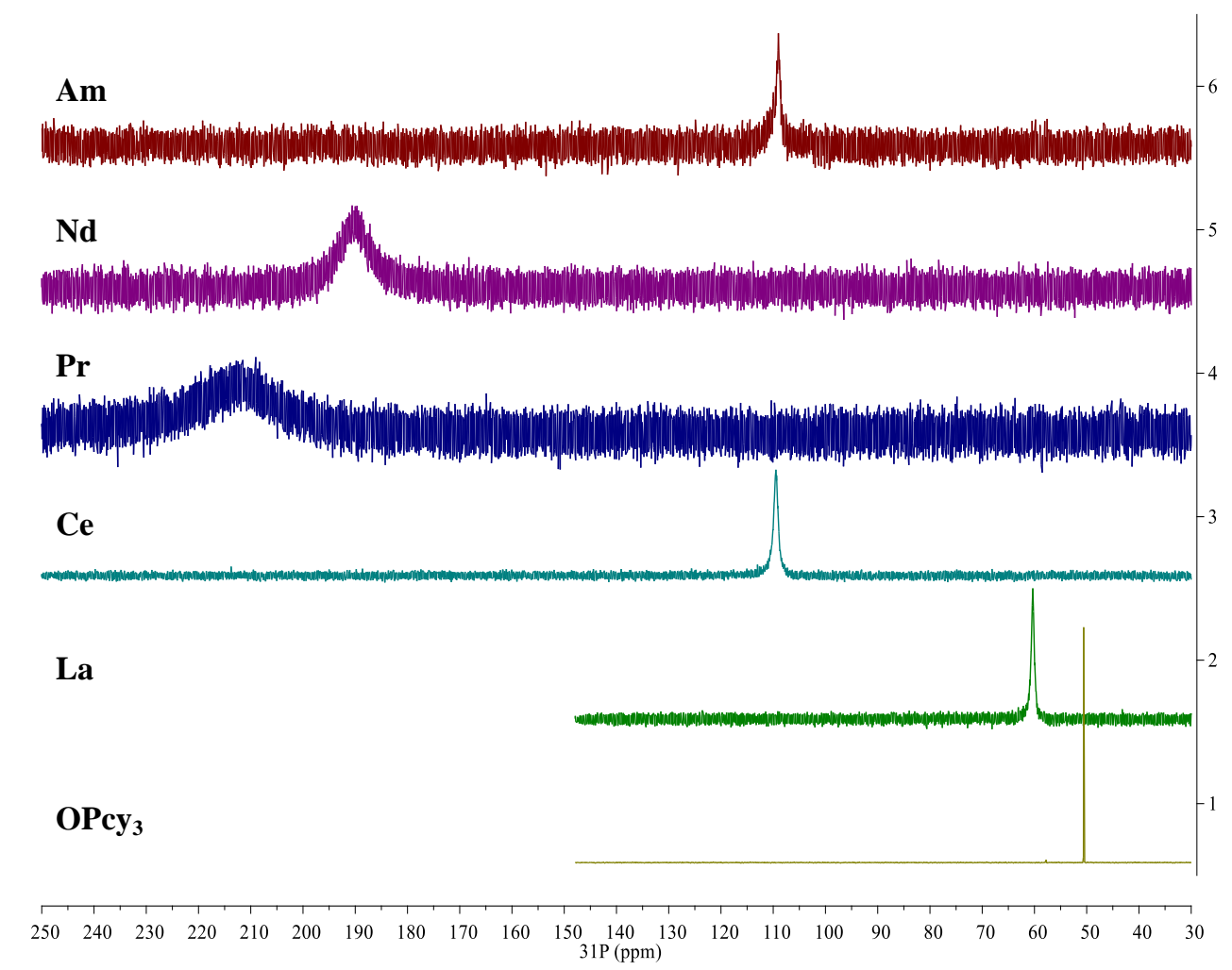

Figure 4. Stacked ${ }^{31} \mathrm{P}\left\{{ }^{1} \mathrm{H}\right\}$ NMR spectra of $\mathbf{M B r}_{\mathbf{3}}\left(\mathbf{O P c y}_{3}\right)_{3}(\mathrm{M}=\mathrm{Am}, \mathrm{Nd}, \mathrm{Pr}, \mathrm{Ce}, \mathrm{La})$ including $\mathrm{OPcy}_{3}$ in $\mathrm{CDCl}_{3}$ at 298-294 K.

\section{Theoretical Analysis}

Bonding Analysis. To obtain a deeper understanding of the bonding in $\mathbf{M B r}_{\mathbf{3}}\left(\mathbf{O P c y}_{\mathbf{3}}\right)_{3}$, a Quantum Theory of Atoms In Molecules (QTAIM) analysis was performed to calculate the concentration of electron density $\rho(\mathrm{r})$, delocalization indices $\delta(\mathrm{r})$, and energy densities [potential, V(r), kinetic, G(r), and total energy densities, H(r)]. All of these metrics are utilized to determine the degree of covalency exhibited in the bonding interactions. Based on previous studies where the nature of bonding interactions of $f$-block complexes has been shown that bonds are not formally covalent, but rather partially covalent. ${ }^{39,}{ }^{40,74}$ A partial covalent bond implies positive values for the Laplacian of the electron density, $\nabla \rho(\mathrm{r})$, and negative values for total energy densities, H(r). Here, the term "covalency" refers to the 
metal-ligand interaction needed to experience orbital overlap, which is reflected by the buildup of electron density $[\rho(\mathrm{r})]$ in the interatomic region. Furthermore, covalency can be enhanced by a better energy match between the atomic orbital involved, which is reflected by the delocalization of the electrons in the interatomic region.
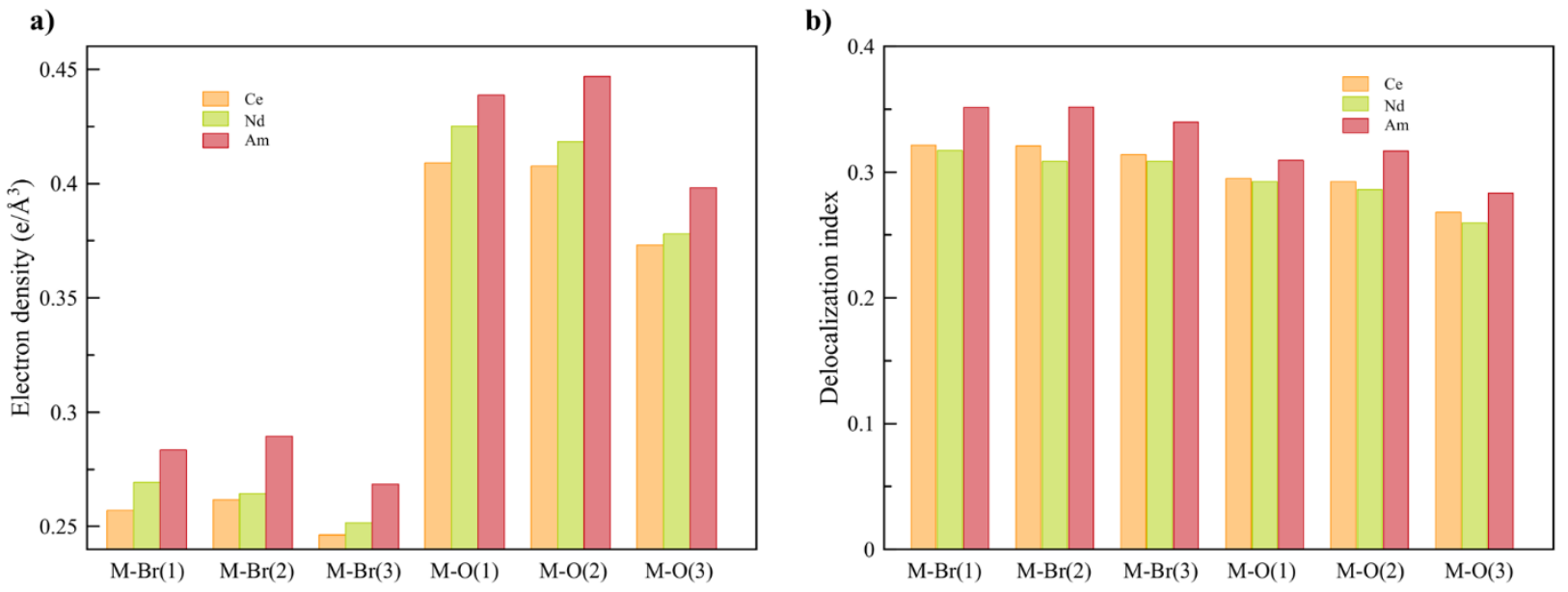

Figure 5. QTAIM metrics of the Bond Critical Points (BCPs) derived from the SR-CAS $(n, 7)$ wave functions, (a, Left) Concentration of the electron density, (b, Right) delocalization indices, and (c) total energy densities. See ESI for exact numbers.

From a general perspective the results herein show that the $\mathrm{M}-\mathrm{Br}$ bonds displays a low concentration of electron density in the interatomic region compared to the $\mathrm{M}-\mathrm{O}$ bonds, Figure 5a, though similar delocalization indices, Figure 5b, implying that the covalency in the $\mathrm{M}-\mathrm{O}$ bonds occur due to increased orbital overlap, whereas the better energy match between parent metal-ligand orbitals for the $\mathrm{M}-\mathrm{Br}$ bonds compensate for the lack of electron density concentration. A more subtle difference is observed in the energy density of the $\mathrm{M}-\mathrm{O}$ bonds, particularly the $\mathrm{M}-\mathrm{O}(3)$ bond where $\mathbf{C e B r}_{3}\left(\mathbf{O P c y}_{3}\right)_{3}$ most resembles $\mathbf{A m B r}_{3}\left(\mathbf{O P c y}_{3}\right)_{3}$. Whereas the $\mathrm{M}-\mathrm{Br}$ bonds of $\mathrm{CeBr}_{3}\left(\mathrm{OPcy}_{3}\right)_{3}$ and $\mathbf{N d B r}_{3}\left(\mathrm{OPcy}_{3}\right)_{3}$ are closer to each other, 
Figure 6a. The origin of these subtleties resides in the balance between kinetic, G(r), and potential energy, $V(r)$, densities with respect to the Laplacian of the electron density, $\nabla \rho(r)$, where a more careful treatment can be done when the total electron densities, $\mathrm{H}(\mathrm{r})$, is normalized by the electron density at the Bond Critical Point (BCP). This allows the role of the kinetic, $\mathrm{G}(\mathrm{r})$, and potential energies, $\mathrm{V}(\mathrm{r})$, to be isolated from the concentration of electron density, $\rho(\mathrm{r})$, Figure $\mathbf{6 b}$. When the data are compared, the same trends are observed. It appears that $\mathrm{CeBr}_{3}\left(\mathrm{OPcy}_{3}\right)_{3}$ and $\mathbf{N d B r}_{3}\left(\mathrm{OPcy}_{3}\right)_{3}$ differ from each other in that: the bonding patterns are independent of the concentration of electron density, $\rho(r)$, i.e. $\mathrm{Ce}$ stabilizes the electrons in the interatomic region similarly to $\mathrm{Nd}$ when a more polarizable ligand is present like $\mathrm{Br}$, while $\mathrm{Ce}$ resembles $\mathrm{Am}$ when a harder-donor ligand is present, like $\mathrm{OPR}_{3}$. Moreover, the dominance of potential energy, $\mathrm{V}(\mathrm{r})$, over kinetic energy, $\mathrm{G}(\mathrm{r})$ is independent of the electron density, which shows that the covalent contribution in $\mathrm{Nd}-\mathrm{O}(3)$ bond is almost negligible, Figure $\mathbf{6 b}$.
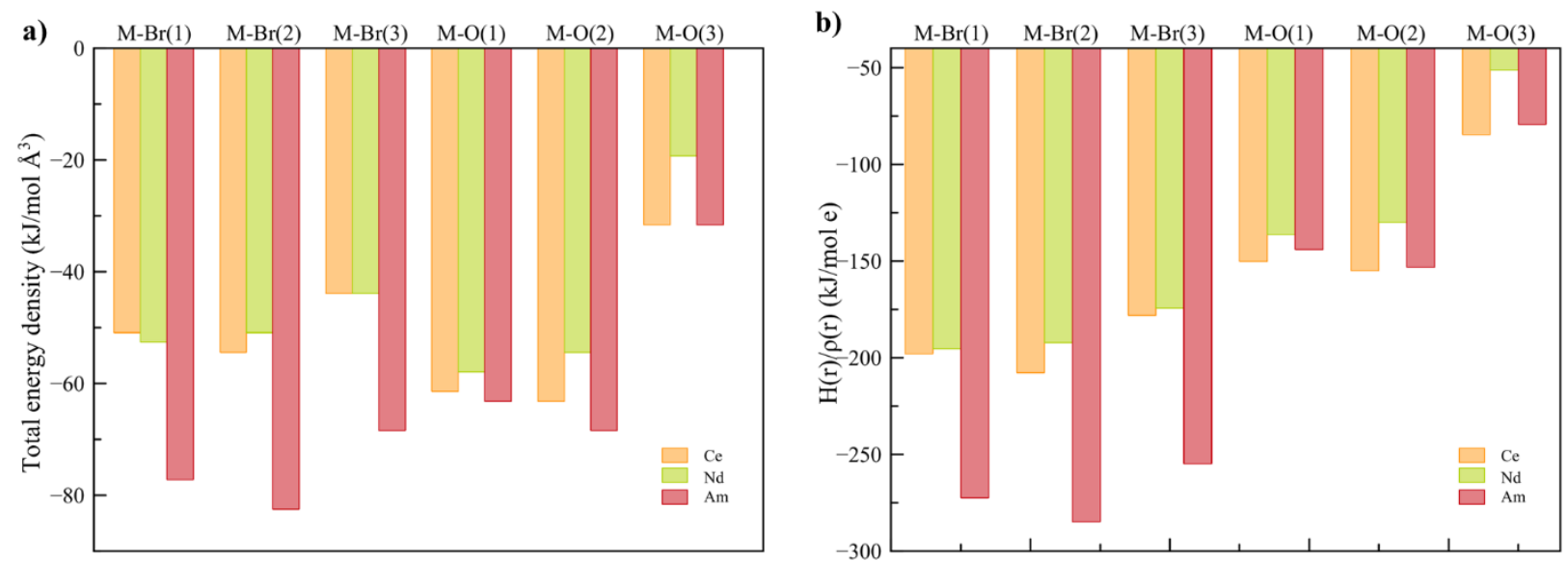

Figure 6. Total energy density over the electron density at the BCP derived from a SRCAS $(7,7)$ wave function. See ESI for exact numbers. 
Table 3. Ratio between potential $[\mathrm{V}(\mathrm{r})]$ and kinetic $[\mathrm{G}(\mathrm{r})]$ energy densities.

\begin{tabular}{|l|ccc|}
\cline { 2 - 4 } \multicolumn{1}{c|}{} & \multicolumn{3}{c|}{$|\mathrm{V}(\mathrm{r})| \mathrm{G}(\mathrm{r})\left(\mathrm{kJ} \mathrm{mol}^{-1} \AA^{-3}\right)$} \\
\hline $\mathrm{Ce}$ & $\mathrm{Nd}$ & $\mathrm{Am}$ \\
$\mathrm{M}(1)-\mathrm{Br}(1)-\mathrm{Br}(2)$ & 1.10 & 1.10 & 1.13 \\
$\mathrm{M}(1)-\mathrm{Br}(3)$ & 1.11 & 1.10 & 1.14 \\
$\mathrm{M}(1)-\mathrm{O}(1)$ & 1.09 & 1.09 & 1.12 \\
$\mathrm{M}(1)-\mathrm{O}(2)$ & 1.05 & 1.04 & 1.04 \\
$\mathrm{M}(1)-\mathrm{O}(3)$ & 1.03 & 1.02 & 1.04 \\
\hline
\end{tabular}

Further characterization of the bonds is provided by the ratio between potential, V(r), and kinetic, $G(r)$, energy densities, that shows the extent of the polarization of the bond, again the $\mathrm{M}-\mathrm{Br}$ bonds are less polarized than the $\mathrm{M}-\mathrm{O}$ bonds, where Am shows the least polarized bonds (down to $86 \%$ of polarization), Table 3 . This agrees with the better energy match provided by $\mathrm{Br}^{-}$with the lanthanides and actinides, but is most pronounced in the Am complex. 


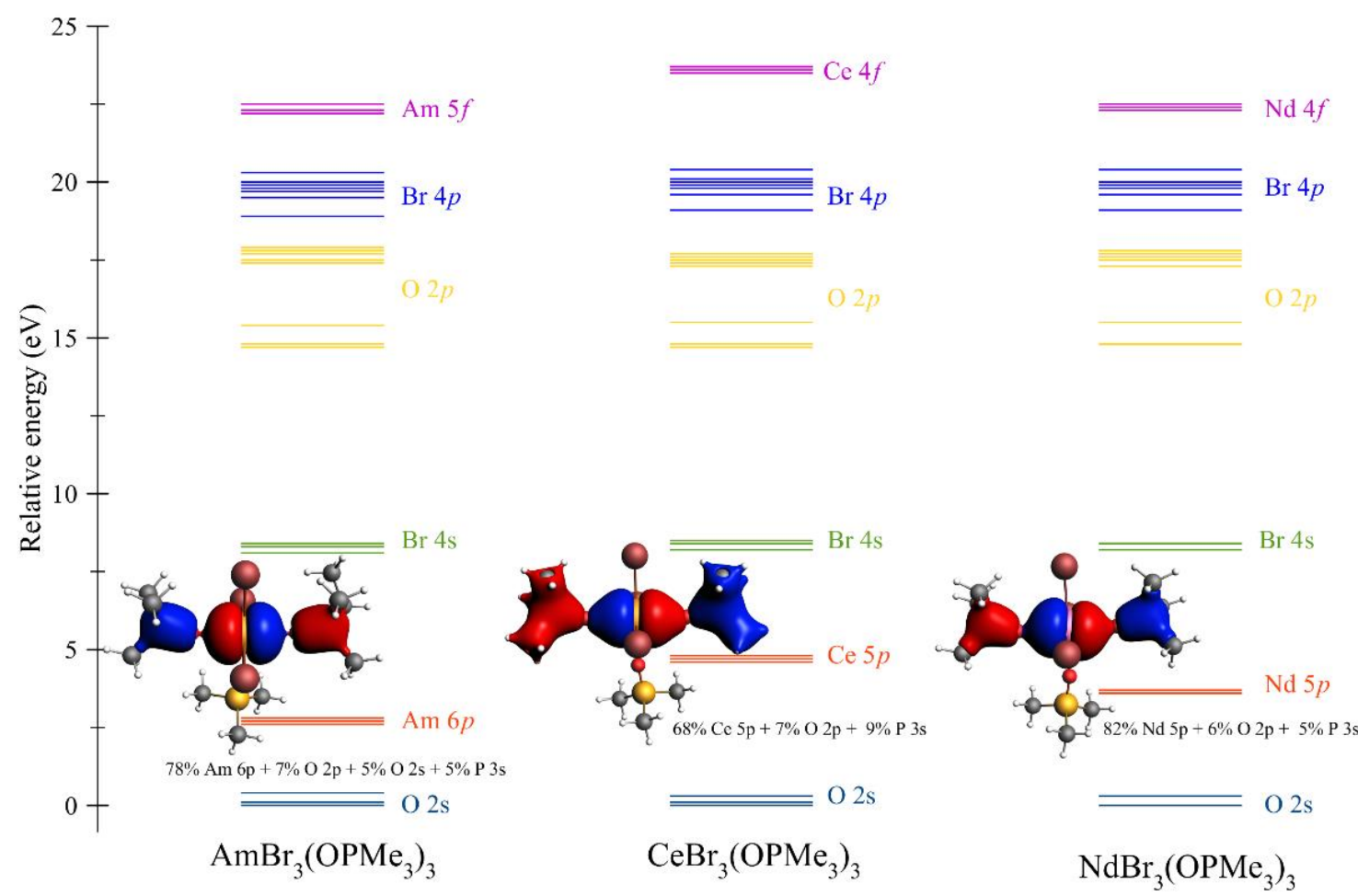

Figure 7. Molecular orbital (MO) energy level diagram for $\mathbf{M B r}_{\mathbf{3}}\left(\mathbf{O P M e}_{3}\right)_{\mathbf{3}}(\mathrm{M}=\mathrm{Am}, \mathrm{Ce}$, Nd) from a scalar relativistic PBE/TZVP calculation. MO labels correspond to the predominant shell in the MO, for the MO composition see Tables S2-S4. MO depictions correspond to the involvement of the semi-core 5/6p orbitals in orbital mixing.

Qualitatively, the ITI correlates with the previous bonding analysis. ${ }^{21}$ However, quantitatively, this does not appear to be the case due to the simple shortening of the bond, which could imply different effects operating simultaneously in the complex. Another way to corroborate the presence of the ITI is by the inclusion of the $5 / 6 p$ orbitals in an all-electron versus a frozen-core calculation.$^{21}$ Our results show that $\mathbf{C e B r}_{\mathbf{3}}\left(\mathbf{O P c y}_{\mathbf{3}}\right)_{3}$ exhibits the highest amount of stabilization $(84.5 \mathrm{~kJ} / \mathrm{mol})$ then $\mathbf{A m B r}_{\mathbf{3}}\left(\mathbf{O P c y}_{3}\right)_{\mathbf{3}}(44.2 \mathrm{~kJ} / \mathrm{mol})$, and $\mathrm{NdBr}_{\mathbf{3}}\left(\mathrm{OPcy}_{\mathbf{3}}\right)_{\mathbf{3}}(35.3 \mathrm{~kJ} / \mathrm{mol})$ shows the least amount of stabilization by the inclusion of the 
$5 / 6 p$ shell, which confirms the presence of the ITI in these systems. However, the energies of stabilization do not correlate with the trend observed for the ITI percentages coming directly from the contraction of the bonds in the trans positions. This is not necessarily true for a system presenting more than one ITI mechanism because they compete within the same molecule, and therefore become more complicated to analyze. For clarity in the construction of an MO energy level diagram, the cyclohexyl rings were truncated to methyl groups, e.g. $\mathrm{MBr}_{3}\left(\mathrm{OPMe}_{3}\right)_{3}$, Figure $7 .^{75}$ This mixing is produced with the $\mathrm{O} 2 p$ and $\mathrm{P} 3 s$ orbitals, providing a more delocalized character of the bond and the stronger mixing between $5 p$ orbitals in Ce is observed, Figure 7.

Another way to show the role of the $\mathrm{Ln} / \mathrm{An} 5 / 6 p$ orbitals in ITI is to assess the reduction of the electron repulsion of these semi-core electrons in the complex with respect to the free-ion. Within ligand field theory (LFT) the one-electron inter-electronic repulsion integrals are described by the Slater-Condon parameters $\mathrm{F}^{\mathrm{k}}(\mathrm{nl}, \mathrm{nl})(\mathrm{n}=$ shell, $1=s, p, d, f)$ and the spin-orbit coupling parameter $\zeta_{n 1}{ }^{76,77}$ Previous studies have successfully applied a nonempirical method to obtain these parameters using a ligand-field DFT (LFDFT) capable of predicting the electronic structure of lanthanide complexes. ${ }^{45,78-81}$ Since the reductions of the Slater-Condon parameters with respect to the free-ion are related to the central-field and symmetry-restricted covalency, their evaluation will provide further insight into the nature of ITI in these complexes.

The reduction of the LF parameters is considerably larger in $\mathbf{C e B r}_{3}\left(\mathbf{O P c y}_{3}\right)_{3}$ compared to $\mathbf{N d B r}_{3}\left(\mathbf{O P c y}_{3}\right)_{3}$ and $\mathbf{A m B r}_{3}\left(\mathbf{O P c y}_{3}\right)_{3}$, whose reductions are similar, Table 4. These results agree with the stabilization energies obtained between frozen-core to allelectron calculations, confirming the presence of ITI. This also shows that the sizable reductions indicate an important covalent component related to the $5 / 6 p$ orbital involvement in the interaction between the metal ions and the $\mathrm{Br}$ and phosphine oxide ligands. 
Table 4. Reduction of the Slater-Condon parameters ${ }^{*}$ of the 5/6p semi-core electrons derived from LF-DFT. $\Delta_{\text {red }}$ refers to the difference between the aquo and $\mathbf{M B r}_{\mathbf{3}}(\mathbf{O P c y})_{\mathbf{3}}(\mathbf{M}=\mathrm{Ce}, \mathrm{Nd}$, Am) complexes.

\begin{tabular}{|c|ccc|ccc|}
\hline & \multicolumn{3}{|c|}{$\mathrm{F}^{2}(\mathrm{p}, \mathrm{p})(\mathrm{eV})$} & \multicolumn{3}{c|}{$\zeta_{5 / 6 p}(\mathrm{eV})$} \\
\hline & {$\left[\mathrm{M}\left(\mathrm{H}_{2} \mathrm{O}\right)_{9}\right]^{3+}$} & $\mathrm{MBr}_{3}(\mathrm{OPcy})_{3}$ & $\Delta_{\text {red }}$ & {$\left[\mathrm{M}\left(\mathrm{H}_{2} \mathrm{O}\right)_{9}\right]^{3+}$} & $\mathrm{MBr}_{3}(\mathrm{OPcy})_{3}$ & $\Delta_{\text {red }}$ \\
\hline $\mathrm{Ce}^{\mathrm{III}}$ & $28 \%$ & $70 \%$ & $42 \%$ & $18 \%$ & $47 \%$ & $29 \%$ \\
\hline $\mathrm{Nd}^{\mathrm{III}}$ & $21 \%$ & $43 \%$ & $22 \%$ & $15 \%$ & $28 \%$ & $13 \%$ \\
\hline $\mathrm{Am}^{\mathrm{III}}$ & $19 \%$ & $45 \%$ & $25 \%$ & $14 \%$ & $27 \%$ & $12 \%$ \\
\hline
\end{tabular}

* See ESI for Slater-Condon parameters

The differences in bonding observed between lanthanides and actinides make the comparison more complicated due to the involvement of the $5 f$ electrons in the case of americium, which significantly increases the covalent character of the bond. In this context, only $\mathrm{Ce}$ and $\mathrm{Nd}$ could be compared with QTAIM metrics, where delocalization and total energy densities predict the trend observed in the stabilization energies from the involvement of the $5 p$ electrons.

\section{Conclusions}

The synthesis and characterization of $\mathbf{A m B r}_{\mathbf{3}}\left(\mathbf{O P c y}_{\mathbf{3}}\right)_{\mathbf{3}}$ has been achieved and shows the same meridinal coordination geometry as the larger lanthanides. Spectroscopic analysis by single crystal X-ray diffraction shows that the homo-trans ligands display significantly short bonds than the hetero-trans ligands. Single crystal UV/vis/NIR spectra show large charge transfer bands for the $\mathrm{Ce}$ and $\mathrm{Am}$ complexes and hypersensitive transitions for the $\mathrm{Nd}$ and $\mathrm{Am}$ 
analogs due to the pseudo-inversion center. Analysis by ${ }^{31} \mathrm{P}$ NMR spectroscopy illustrates the weak paramagnetism of the $5 f^{6} \mathrm{Am}^{3+}$ center. Bonding analyses show that the complex displays a significant inverse trans influence (ITI) with the bonding ligands, though its mechanism is not directly related to the involvement of the $5 / 6 p$ electrons. This suggests that there is an interplay between the involvement of valence electrons that significantly separates the lanthanides from the actinides. It is surprising that Ce shows the highest amount of $5 p$ electron involvement in covalency. This is observed by the reduction of the electronelectron repulsion of the $5 p$ shell compared to the aquo-complex, $\left[\mathrm{Ce}\left(\mathrm{H}_{2} \mathrm{O}\right)_{9}\right]^{3+}$. This study provides further evidence of ITI in low-valent $f$-block complexes, and their potential occurrence in heavier actinides, whose chemistry is dominated by the trivalent oxidation state. Furthermore, it constitutes a new feature that can be exploited for rational ligand design in order to achieve selective ligands for separations in nuclear waste treatment.

\section{Conflicts of interest}

The authors declare no competing financial interest

\section{Acknowledgements}

We thank the support of the U.S. Department of Energy, Office of Science, Office of Basic Energy Sciences, Heavy Element Chemistry program under Award Number DE-FG0213ER16414. The isotopes used in this research were supplied by the U.S. Department of Energy Isotope Program, managed by the Office of Science for Nuclear Physics. We thank Benjamin W. Stein and Conrad A. P. Goodwin of Los Alamos National Laboratory for helpful discussions. We are grateful to Dr. Banghao Chen for his assistance with the NMR experiments. We thank Jason Johnson and Ashley Gray of Florida State University for radiological assistance. 


\section{Notes and References}

1. V. V. Grushin, Chem. Rev., 2004, 104, 1629-1662.

2. E. K. Watson and W. A. Rickelton, Solvent Extr. Ion Exch., 1992, 10, 879-889.

3. F. Arnaud-Neu, J. K. Browne, D. Byrne, D. J. Marrs, M. A. McKervey, P. O'Hagan, M. J. Schwing-Weill and A. Walker, Chem. Eur. J., 1999, 5, 175-186.

4. M. Gilmore, É. N. McCourt, F. Connolly, P. Nockemann, M. Swadźba-Kwaśny and J. D. Holbrey, ACS Sustainable Chem. Eng., 2018, 6, 17323-17332.

5. L. R. Morss, N. M. Edelstein and J. Fuger, The Chemistry of the Actinide and Transactinide Elements, Springer, Dordrecht, The Netherlands, 4th edn., 2010.

6. S. Mishra, Coord. Chem. Rev., 2008, 252, 1996-2025.

7. C. Berthon, N. Boubals, I. A. Charushnikova, D. Collison, S. M. Cornet, C. Den Auwer, A. J. Gaunt, N. Kaltsoyannis, I. May, S. Petit, M. P. Redmond, S. D. Reilly and B. L. Scott, Inorg. Chem., 2010, 49, 9554-9562.

8. M. B. Jones and A. J. Gaunt, Chem. Rev., 2013, 113, 1137-1198.

9. A. W. G. Platt, Coord. Chem. Rev., 2017, 340, 62-78.

10. R. G. Denning, J. Phys. Chem. A, 2007, 111, 4125-4143.

11. T. J. Emge, A. Kornienko and J. G. Brennan, Acta Cryst., 2009, C65, m422-m425.

12. K. Krogh-Jespersen, M. D. Romanelli, J. H. Melman, T. J. Emge and J. G. Brennan, Inorg. Chem., 2010, 49, 552-560.

13. A. J. Lewis, K. C. Mullane, E. Nakamaru-Ogiso, P. J. Carroll and E. J. Schelter, Inorg. Chem., 2014, 53, 6944-6953.

14. H. S. La Pierre, M. Rosenzweig, B. Kosog, C. Hauser, F. W. Heinemann, S. T. Liddle and K. Meyer, Chem. Commun. (Camb), 2015, 51, 16671-16674.

15. M. Gregson, E. Lu, D. P. Mills, F. Tuna, E. J. McInnes, C. Hennig, A. C. Scheinost, J. McMaster, W. Lewis, A. J. Blake, A. Kerridge and S. T. Liddle, Nat. Commun., 2017, 8, 14137.

16. I. Fryer-Kanssen and A. Kerridge, Chem. Commun. (Camb), 2018, 54, 9761-9764.

17. E. Lu, S. Sajjad, V. E. J. Berryman, A. J. Wooles, N. Kaltsoyannis and S. T. Liddle, Nat. Commun., 2019, 10, 634.

18. B. J. Coe and S. J. Glenwright, Coord. Chem. Rev., 2000, 203, 5-80.

19. A. J. Lewis, P. J. Carroll and E. J. Schelter, J. Am. Chem. Soc., 2013, 135, 1318513192. 
20. T. P. Gompa, N. T. Rice, D. R. Russo, L. M. Aguirre Quintana, B. J. Yik, J. Bacsa and H. S. La Pierre, Dalton Trans., 2019, 48, 8030-8033.

21. E. O'Grady and N. Kaltsoyannis, Dalton Trans., 2002, 1233-1239.

22. P. I. Matveev, N. E. Borisova, N. G. Andreadi, G. G. Zakirova, V. G. Petrov, E. V. Belova, S. N. Kalmykov and B. F. Myasoedov, Dalton Trans., 2019, 48, 2554-2559.

23. J. F. Corbey, B. M. Rapko, Z. Wang, B. K. McNamara, R. G. Surbella, III, K. L. Pellegrini and J. M. Schwantes, Inorg. Chem., 2018, 57, 2278-2287.

24. J. N. Cross, J. A. Macor, J. A. Bertke, M. G. Ferrier, G. S. Girolami, S. A. Kozimor, J. R. Maassen, B. L. Scott, D. K. Shuh, B. W. Stein and S. C. Stieber, Angew. Chem., Int. Ed., 2016, 55, 12755-12759.

25. APEX3, 2017.3-0, Bruker AXS, Inc.: Madison, WI, 2017.

26. SAINT, 8.34a; Bruker AXS, Inc: Madison, WI, 2013.

27. G. M. Sheldrick, SADABS, 2012/1; Bruker AXS, Inc: Madison, WI, 2012.

28. G. M. Sheldrick, Acta Cryst., 2015, A71, 3-8.

29. G. M. Sheldrick, Acta Cryst. , 2015, C71, 3-8.

30. O. V. Dolomanov, L. J. Bourhis, R. J. Gildea, J. A. K. Howard and H. Puschmann, J. Appl. Crystallogr., 2009, 42, 339-341.

31. P.-Å. Malmqvist and B. O. Roos, Chem. Phys. Lett., 1989, 155, 189-194.

32. F. Neese, WIREs Comput. Mol. Sci., 2018, 8, e1327.

33. N. Kaltsoyannis, Inorg. Chem., 2013, 52, 3407-3413.

34. Q. R. Huang, J. R. Kingham and N. Kaltsoyannis, Dalton Trans., 2015, 44, 2554-2566.

35. I. Fryer-Kanssen, J. Austin and A. Kerridge, Inorg. Chem., 2016, 55, 10034-10042.

36. A. Kerridge, Chem. Commun., 2017, 53, 6685-6695.

37. F. D. White, A. N. Gaiser, E. J. Warzecha, J. M. Sperling, C. Celis-Barros, S. R. Salpage, Y. Zhou, T. Dilbeck, A. J. Bretton, D. S. Meeker, K. G. Hanson and T. E. Albrecht-Schmitt, Inorg. Chem., 2018, 57, 12969-12975.

38. B. E. Klamm, C. J. Windorff, C. Celis-Barros, M. L. Marsh, D. S. Meeker and T. E. Albrecht-Schmitt, Inorg. Chem., 2018, 57, 15389-15398.

39. E. Warzecha, C. Celis-Barros, T. Dilbeck, K. Hanson and T. E. Albrecht-Schmitt, Inorg. Chem., 2019, 58, 228-233.

40. A. T. Chemey, C. Celis-Barros, K. Huang, J. M. Sperling, C. J. Windorff, R. E. Baumbach, D. E. Graf, D. Páez-Hernández, M. Ruf, D. E. Hobart and T. E. AlbrechtSchmitt, Inorg. Chem., 2019, 58, 637-647. 
41. D. Dan, C. Celis-Barros, F. D. White, J. M. Sperling and T. E. Albrecht-Schmitt, Chem. Eur. J., 2019, 25, 3248-3252.

42. E. Espinosa, I. Alkorta, J. Elguero and E. Molins, J. Chem. Phys., 2002, 117, 55295542 .

43. G. te Velde, F. M. Bickelhaupt, E. J. Baerends, C. Fonseca Guerra, S. J. A. van Gisbergen, J. G. Snijders and T. Ziegler, J. Comput. Chem., 2001, 22, 931-967.

44. C. Fonseca Guerra, J. G. Snijders, G. te Velde and E. J. Baerends, Theor. Chem. Acc., 1998, 99, 391-403.

45. H. Ramanantoanina, W. Urland, F. Cimpoesu and C. Daul, Phys. Chem. Chem. Phys., 2013, 15, 13902-13910.

46. M. Atanasov, C. A. Daul and C. Rauzy, in Optical Spectra and Chemical Bonding in Inorganic Compounds: Special Volume dedicated to Professor Jørgensen I, eds. D. M. P. Mingos and T. Schönherr, Springer Berlin Heidelberg, Berlin, Heidelberg, 2004, pp. 97-125.

47. P. Lindqvist-Reis, C. Apostolidis, J. Rebizant, A. Morgenstern, R. Klenze, O. Walter, T. Fanghänel and R. G. Haire, Angew. Chem. Int. Ed., 2007, 46, 919-922.

48. R. E. Gerkin and W. J. Reppart, Acta Cryst. 1984, C40, 781-786.

49. Y. V. Nelyubina, L. N. Puntus and K. A. Lyssenko, Chem. Eur. J., 2014, 2860-2865.

50. A. Bowden, A. M. J. Lees and A. W. G. Platt, Polyhedron, 2015, 91, 110-119.

51. J. V. Kingston, E. M. Krankovits and R. J. Magee, Inorg. Nucl. Chem. Lett., 1969, 5, 485-489.

52. M. J. Glazier, W. Levason, M. L. Matthews, P. L. Thornton and M. Webster, Inorg. Chim. Acta, 2004, 357, 1083-1091.

53. N. J. Hill, W. Levason, M. C. Popham, G. Reid and M. Webster, Polyhedron, 2002, 21, 445-455.

54. A. M. J. Lees and A. W. G. Platt, Polyhedron, 2014, 67, 368-372.

55. Y. C. Chen, J. L. Liu, L. Ungur, J. Liu, Q. W. Li, L. F. Wang, Z. P. Ni, L. F. Chibotaru, X. M. Chen and M. L. Tong, J. Am. Chem. Soc., 2016, 138, 2829-2837.

56. Y. X. Wang, Y. Ma, Y. Chai, W. Shi, Y. Sun and P. Cheng, J. Am. Chem. Soc., 2018, 140, 7795-7798.

57. S. S. Galley, J. M. Sperling, C. J. Windorff, M. Zeller, T. E. Albrecht-Schmitt and S. C. Bart, Organometallics, 2019, 38, 606-609.

58. H. Flack, Acta Cryst., 1983, A39, 876-881.

59. R. Shannon, Acta Cryst., 1976, A32, 751-767. 
60. L. J. Radonovich and M. D. Glick, J. Inorg. Nucl. Chem., 1973, 35, 2745-2752.

61. X.-W. Zhang, X.-F. Li, F. Benetollo and G. Bombieri, Inorg. Chim. Acta, 1987, 139, 103-104.

62. Z. Hou, K. Kobayashi and H. Yamazaki, Chem. Lett., 1991, 20, 265-268.

63. G. B. Deacon, T. Feng, P. C. Junk, B. W. Skelton, A. N. Sobolev and A. H. White, Aust. J. Chem., 1998, 51, 75-89.

64. G. B. Deacon, T. Feng, P. C. Junk, G. Meyer, N. M. Scott, B. W. Skelton and A. H. White, Aust. J. Chem., 2000, 53, 853 - 865.

65. W. T. Carnall and B. G. Wybourne, J. Chem. Phys., 1964, 40, 3428-3433.

66. R. G. Pappalardo, W. T. Carnall and P. R. Fields, J. Chem. Phys., 1969, 51, 1182-1200.

67. J. N. Cross, J. Su, E. R. Batista, S. K. Cary, W. J. Evans, S. A. Kozimor, V. Mocko, B. L. Scott, B. W. Stein, C. J. Windorff and P. Yang, J. Am. Chem. Soc., 2017, 139, 86678677.

68. B. R. Judd, J. Chem. Phys., 1966, 44, 839-840.

69. D. E. Henrie, R. L. Fellows and G. R. Choppin, Coord. Chem. Rev., 1976, 18, 199-224.

70. K. Binnemans and C. Görller-Walrand, Chem. Phys. Lett., 1995, 235, 163-174.

71. T. F. Wall, S. Jan, M. Autillo, K. L. Nash, L. Guerin, C. L. Naour, P. Moisy and C. Berthon, Inorg. Chem., 2014, 53, 2450-2459.

72. L. Martel, N. Magnani, J. F. Vigier, J. Boshoven, C. Selfslag, I. Farnan, J. C. Griveau, J. Somers and T. Fanghanel, Inorg. Chem., 2014, 53, 6928-6933.

73. C. A. P. Goodwin, J. Su, T. E. Albrecht-Schmitt, A. V. Blake, E. R. Batista, S. R. Daly, S. Dehnen, W. J. Evans, A. J. Gaunt, S. A. Kozimor, N. Lichtenberger, B. L. Scott and P. Yang, Angew. Chem., Int. Ed., 2019, 58, 11695-11699.

74. C. Celis-Barros, D. Paez-Hernandez, M. J. Beltran-Leiva and R. Arratia-Perez, Phys. Chem. Chem. Phys., 2018, 20, 4038-4049.

75. The truncated molecules were utilized to remove $\mathrm{C}-\mathrm{C}$ and $\mathrm{C}-\mathrm{H}$ interactions of similar energy from the MO calculations, calculations on the metal-ligand interactions were shown to be the same on the full and truncated molecules, see experimental and ESI for further details.

76. A. B. P. Lever, Inorganic electronic spectroscopy A. B. P. Lever, Elsevier Pub. Co, Amsterdam, New York, 1968.

77. E. U. Condon and G. Shortley, The theory of atomic spectra, Cambridge University Press, Cambridge, 1951. 
78. H. Ramanantoanina, W. Urland, B. Herden, F. Cimpoesu and C. Daul, Phys. Chem. Chem. Phys., 2015, 17, 9116-9125.

79. H. Ramanantoanina, M. Sahnoun, A. Barbiero, M. Ferbinteanu and F. Cimpoesu, Phys. Chem. Chem. Phys., 2015, 17, 18547-18557.

80. H. Ramanantoanina, W. Urland, A. García-Fuente, F. Cimpoesu and C. Daul, Chem. Phys. Lett., 2013, 588, 260-266.

81. H. Ramanantoanina, F. Cimpoesu, C. Göttel, M. Sahnoun, B. Herden, M. Suta, C. Wickleder, W. Urland and C. Daul, Inorg. Chem., 2015, 54, 8319-8326. 


\section{TOC Image}

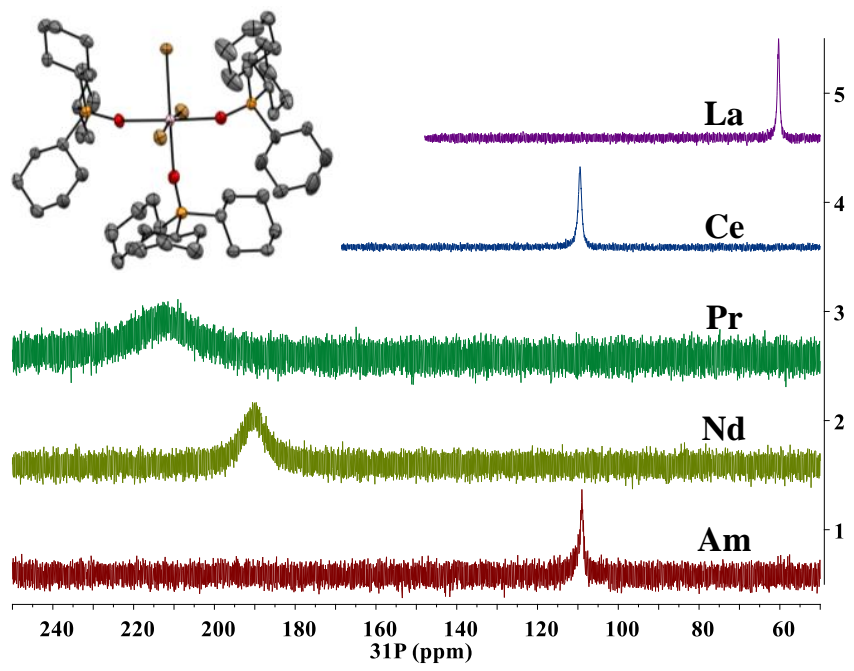

